\title{
Steps to a Good Night's Sleep: The Association Between Physical Activity and Sleep in early Adolescence
}

Chiara E. G. Fontanellaz-Castiglione

University of Bern

Tammy T. Timmers

University of Bern

Stefan Lerch

University of Bern

Christoph Hamman

University Children's Hospital, Inselspital, University of Bern

Michael Kaess

University of Bern

Leila Tarokh ( $\nabla$ leila.tarokh@upd.unibe.ch )

University of Bern

\section{Research Article}

Keywords: Adolescence, Sleep, Physical activity, Actigraphy

Posted Date: February 18th, 2022

DOI: https://doi.org/10.21203/rs.3.rs-1327550/v1

License: (1) This work is licensed under a Creative Commons Attribution 4.0 International License.

Read Full License 


\section{Abstract \\ Purpose}

Research to date suggests that physical activity is associated with improved sleep, but studies have predominantly relied on self-report measures and have not accounted for school day/free day variability.

\section{Methods}

To address these gaps in the literature, the aim of the present study was to describe the number of steps in adolescents using long-term daily actigraphy measurement (5,989 days in total; average of $119 \pm 40$ days per participant; range $=39-195$ days) and examine the association between actigraphically assessed steps and sleep behavior (i.e., total sleep time, bedtime, rise time and sleep efficiency) in a sample of healthy adolescents $(\mathrm{N}=50)$. We use multilevel modeling to disentangle the within subject and between subject effects of physical activity on sleep.

\section{Results}

Within a subject more steps on school and free days were associated with later bed times as well as later rise times on school days. On the other hand, comparing between subjects' effects, steps were associated with lower sleep efficiency on free and school days. No other significant associations were found for the other sleep variables.

\section{Conclusion}

Our results obtained through objective and long-term measurement of both sleep and steps challenge previous findings showing a positive effect of physical activity on sleep. We emphasize the importance of the methodology and the separation of within subject from between subject features when examining the relationship between physical activity and sleep.

\section{Background}

Children making the transition to adolescence experience marked changes in sleep behavior. The most striking of these changes is a trend towards later bedtimes, which has consistently been shown worldwide in this age group [1]. This delay in bedtime is driven by biological changes to the circadian timing system $[2,3]$ which favors later bedtimes in adolescence and is further exacerbated by environmental and psychosocial factors, such as homework, after-school activities, autonomy from parents, socialization and the use of technology (e. g. $[4,5])$. Despite going to bed later, on school days adolescents wake up as early or even earlier than they did during mid and late childhood due to school start times [6], resulting in an overall decrease of total sleep duration and making them one of the most 
sleep deprived age groups [7]. Many adolescents attempt to make up for the accumulated sleep deficit during the school week with longer sleep on weekends [1]. This trend of inadequate and ill-timed sleep represents a major public health concern (e. g. $[8,9])$. There is ample evidence that insufficient sleep negatively impacts many domains of a teenager's life, including cognitive functioning [10-13], academic performance [7, 14]] and mental health [15-17]. Therefore, it is critical to identify factors that may facilitate healthier sleep patterns in this population; one such factor may be physical activity [18-20].

The idea that a physically demanding day will lead to a good night's sleep has existed since Biblical times "Sweet is the sleep of a laboring man..." (Ecclesiastes 5:11 as cited in [21]. Recent and large epidemiological surveys consistently show that regular physical activity is believed to be the most important sleep promoting behavior by the general public $[22,23]$ and many sleep experts consider it a non-pharmacological and cost-effective sleep aid [24, 25]. Despite the assumption that exercise has a beneficial effect on sleep, the empirical evidence supporting this assertion is inconclusive [25, 26]. A number of observational and experimental studies have found greater physical activity to be associated with less daytime sleepiness (measured subjectively) [27] earlier bedtimes (measured subjectively and objectively) [28], shortened latency to fall asleep (measured subjectively and objectively) and fewer awakenings at night (measured subjectively and objectively) [29-31]. Most recently, a multinational study of 5,779 children aged 9-11 years found that moderate-to-vigorous intensity physical activity measured with a waist-worn actigraph was associated with longer sleep duration measured with the same device. However the effect sizes in this study were small [32].

In contrast, opposite and null effects of exercise on sleep have also been reported for children, adolescents and adults [33-35]. For example, Youngstedt and colleagues conducted two prospective studies examining the association between physical activity and sleep in young and older adults [36]. In the first study, 31 college students kept a diary for 105 consecutive days documenting their total exercise duration and a host of sleep variables including measures of sleep duration and quality. In the second study of older adults, 71 participants wore an actigraphy to measure physical activity and reported on their sleep using sleep diaries for seven consecutive days. In both studies, no noteworthy correlations were found between physical activity and sleep. Two further studies examining daytime physical activity and sleep in pre-adolescents (age 6-10 years) using actigraphy for seven consecutive days indicated that more physical activity was associated with more frequently interrupted sleep [37] and decreased sleep duration and sleep efficiency [38] on the following night.

From a methodological point of view, the mixed results from the studies described above may be attributed to different modes of measuring physical activity and sleep, which ranged from self-report questionnaires (often only comprised of one or two questions; [39] to objective measures via actigraphy and polysomnography. Interestingly, a systematic review of physical activity and sleep reported that of 21 studies only two studies relied exclusively upon objective measures [39]. Although self-report measures are often used due to their feasibility and cost-effectiveness, they have been shown to be inaccurate in younger populations. Adolescents tend to overestimate their physical activity levels, especially their vigorous physical activity [30] and may in particular report the most recent, salient and/or socially 
desirable patterns of sleep [39]. In a meta-analytic review, acute exercise was found to have limited beneficial effects on measures of sleep (e.g. total sleep time, sleep onset latency and sleep efficiency). Regular exercise instead was found to have a small positive influence on total sleep time and sleep efficiency, small to medium positive influence on sleep onset latency and a moderate positive influence on sleep quality [18].

The duration for which physical activity and sleep are measured may further muddle results. While appropriate measurement periods are device dependent, most studies examined exercise and sleep for only one or two days [36]. Prior research suggests that in order to achieve a reliability of 0.80 in adolescents, 8-9 days and 6-7 nights are required for valid actigraphy measured physical activity and sleep outcomes, respectively $[40,41]$. Furthermore, if the measurement period is less than one week, care must be taken to include both school day and free day activities given the large differences in sleep [42]and physical activity [43] on free days as compared to school days [41].

Therefore, the aim of the present study was to overcome methodological limitations in previous studies by investigating the association between physical activity and sleep using long-term (i.e., several months) objective measurement of both factors in adolescents on both school and free days. Based on results from earlier research, we hypothesize that physical activity will differ on school as compared to free days [43]. With regards to sleep, results for this data set have previously been published [44], and as expected based on the existing literature sleep was shorter on school days as compared to free days and sleep duration declined with increasing age. Finally, despite inconsistent findings in the literature, we hypothesize that higher actigraphy-assessed physical activity in adolescents will be associated with better objective sleep.

\section{Methods}

\section{Participants}

Participants were recruited through flyers, advertisements and direct mailings to schools in the German speaking part of Switzerland as part of a twin study examining the heritability of sleep neurophysiology and behavior [44-49]. Exclusion criteria included suffering from a chronic or current illness, use of medications affecting sleep and brain function, known sleep disorders, and preterm birth before the $30^{\text {th }}$ gestation week. The ethics commission of the canton of Zurich approved the study and participants and their parents provided written informed consent.

Participants with a minimum of 30 days of activity and sleep data were included in the analyses; eleven participants ( 7 girls, 4 boys) were excluded from the analyses because they did not meet this criteria. Therefore, the analysis is based on 50 participants with complete data ( 24 girls, 26 boys aged $12.78, \pm$ 1.02 years). Mean body mass index was in the healthy range for adolescents (mean $=17.77$; range $=$ 13.88 - 22.03; $S D=1.95)$.

\section{Procedures}


Steps were assessed objectively and non-invasively with the Jawbone UP triaxial accelerometer (Jawbone, San Francisco, CA, USA) which participants wore on their non-dominant wrist. Participants were instructed to wear the Jawbone UP at all times for six months except while swimming or bathing. The Jawbone UP is considered an accurate and reliable device for monitoring physical activity [50], showing a test-retest reliability as revealed through an intra-class coefficient (ICC) of 0.97 for step count and 0.60 for active time [51]. Given the lower test-retest reliability of active time, we use number of step count for further analysis. The activity charts of every measurement day were visually inspected and data was excluded from the analyses if sequences during the waking hours indicated two or more consecutive hours of idle time, suggesting that the monitor had been removed from the body. Thus, in total 5,989 days of data were available for analysis. The average number of school days available for analysis was 66.86 \pm 22.59 days (range: 22 - 108 days) per participant while the number of free days (defined as weekends and holidays) ranged between 16 and 93 days with a mean of $52.92 \pm 19.95$ days per participant. We note that we use steps as a proxy for physical activity and thus use the terms physical activity and steps interchangeably.

The same activity monitor (Jawbone UP) was also used to assess sleep behavior across the 6-month interval. This device has also been validated for the measurement of sleep in adolescents [52].

Participants were instructed to press a button on the wristband before bed in the evening and upon waking in the morning to switch the device from the "active" to the "sleep" mode. If participants did not press the button to activate the sleep mode or active mode, the data was not included in the analysis. Using proprietary algorithms Jawbone UP calculates the following variables with minute precision for each night: Bed time, wake time, total sleep time (TST), sleep onset latency (SOL; time between going to bed and falling asleep), wake after sleep onset (WASO; time spent awake after sleep onset, often also referred as sleep fragmentation), number of awakenings (NOA) and sleep efficiency (SE; ratio of sleep time to time in bed). Because sleep efficiency is a composite measure taking SOL, NOA, and WASO into account we use SE as our outcome variable along with TST and bed and rise times. As with steps, analyses were performed separately for school and free days.

For the present study the association between steps during the day and sleep on the subsequent night both measured via actigraphy was examined. Participant were instructed to wear actigraphy devices daily for six months and only remove the device when swimming.

\section{Statistical Analyses}

In order to assess the impact of gender, age, and day type on steps, we performed a linear mixed model with random intercept grouped by subjects. For the analysis, age was centered by the sample mean (12.78 years) and the interaction of gender and day type was taken into account.

Second, mixed models for four sleep outcomes were calculated to examine the effect of number of steps on sleep. Our predictor, physical activity described as steps per day was split into within and between subject measures. To perform between subject analyses, the mean number of steps across all measurements days was calculated for each individual (STEPS_M) resulting in one value per participant. 
In order to examine whether within an individual, days with more steps were associated with more sleep on the subsequent night, we adjusted for baseline levels of steps by subtracting the mean across all days for an individual by the number of steps per day (STEPS_D). Our sleep outcome variables were total sleep time, bedtime, rise time and sleep efficiency.

Two-level mixed-effects regression analyses with robust variance estimation and standard errors were used to investigate the effect of age, gender, day type (school day versus free day) and number of steps on sleep. For each sleep outcome a separate mixed effect model is estimated. Data are grouped by subject, where we allow for a random intercept. To account for the different activity levels on school and free days, we included the interaction term DAYTYPE x STEPS_M (between subject analysis) and DAYTYPE x STEPS_D (within subject analysis), respectively. We use Cohen's $f^{2}$ to determine effect sizes [53]. Statistical significance was set to $a=0.05$. All analyses were conducted in Stata/SE 16.1 [54].

\section{Results}

Results examining the impact of demographic variables and day type on steps are reported in Table 1.

Table 1

Results of the model examining the impact of age, gender, and day type (school versus free day) on number of steps. Fixed factors are shown and steps are measured in units of 1000 steps. Gender, Day Type, and Age were significant predictors of steps. Cohen's $f^{2}$ is used as a measure of effect size. All effect sizes are small.

\begin{tabular}{|llllll|}
\hline Factor & Coefficient & Cohens $^{2}$ & $\mathbf{z}$ & $\mathbf{P}$ & $95 \% \mathbf{C l}$ \\
\hline $\begin{array}{l}\text { Gender } \\
\text { (Girl) }\end{array}$ & -1.65 & $<0.001$ & -2.57 & 0.01 & $-2.92,-0.40$ \\
\hline $\begin{array}{l}\text { Day Type } \\
\text { (Free Day) }\end{array}$ & -1.63 & 0.013 & -3.71 & 0.00 & $-2.49,-0.76$ \\
\hline Interaction & -0.27 & $<0.001$ & -0.45 & 0.65 & $-1.43,0.89$ \\
(Girl x Free Day) & & & & & \\
\hline Age & -0.80 & $<0.001$ & -3.36 & 0.00 & $-1.26,-0.33$ \\
\hline Intercept & 23.35 & $<0.001$ & 7.58 & 0.00 & $17.32,29.39$ \\
\hline
\end{tabular}

Averaging across days and participants, 11,609 steps were taken daily. We note, that the within subject variability (i.e., standard deviation) in the number of steps (4,918 steps) is about 2.4 times higher as compared to the between subject variability (2,087 steps) suggesting that while some adolescents were on average more active than others, there is a high day-to-day variation in the number of steps of an individual. This is also reflected in the intraclass correlation coefficient (ICC) for steps which was 0.10 (Cl; $0.08,0.14$ ). Boys took significantly more steps than girls, with girls taking on average 1,650 steps less 
than boys ( $p=0.01$; Fig. 1 ). Both boys and girls were significantly more active on school days as compared to free days, with an average of 1,630 (1,900 for girls) fewer steps taken on free as compared to school days ( $p<0.001$, Fig. 1). Furthermore, a significant decline in the number of steps was observed with age $(p<0.001)$, with each year accounting for 800 fewer steps $(p<0.001)$.

Results showing the association between step count and sleep are presented in Table 2. Within subjects analyses revealed that taking more steps on school and free days was associated with later bedtimes ( $\mathrm{z}$ $=2.37, \mathrm{p}<0.05, \mathrm{f}^{2}=0.00$, free days; $\mathrm{z}=6.43, \mathrm{p}<0.001, \mathrm{f}^{2}=0.01$, school days). In other words, within an individual 1,000 more steps was associated with a bedtime that was 1 minute later. Moreover, more steps were associated with later rise times the following morning on school $\left(z=3.10, p<0.01, f^{2}=0.00\right)$, but not free days $\left(z=1.76, p=0.08, f^{2}=0.00\right)$. On school days, taking 1,000 steps more was associated with a rise time that was 1.07 minutes later. No within subject associations were found between steps and total sleep time and sleep efficiency (see Table 2). 
Table 2

Results of model with fixed factor and subject as random effect. In this table findings are divided between within and between subjects effects and free and school days. In this table, TST = total sleep time; SE = sleep efficiency. . Data is reported in thousand steps (ksteps).

\begin{tabular}{|c|c|c|c|c|c|}
\hline Factor & Coefficient & Cohens $\mathrm{f}^{2}$ & $\mathbf{z}$ & $\mathbf{p}$ & $95 \% \mathrm{Cl}$ \\
\hline \multicolumn{6}{|c|}{ Bedtime (in minutes) } \\
\hline $\begin{array}{l}\text { Steps } \\
\text { (between subjects; free day) }\end{array}$ & 0.92 & $1.844 \mathrm{e}-06$ & 0.37 & 0.70 & $-3.88,5.71$ \\
\hline $\begin{array}{l}\text { Steps } \\
\text { (between subjects; school day) }\end{array}$ & -1.95 & $9.418 \mathrm{e}-06$ & -1.05 & 0.29 & $-5.60,1.70$ \\
\hline $\begin{array}{l}\text { Steps } \\
\text { (within subjects; free day) }\end{array}$ & 1.00 & 0.004 & 2.37 & 0.02 & $0.18,1.84$ \\
\hline $\begin{array}{l}\text { Steps } \\
\text { (within subjects; school day) }\end{array}$ & 1.89 & 0.010 & 6.43 & 0.00 & $1.32,2.50$ \\
\hline \multicolumn{6}{|c|}{ Rise time (in minutes) } \\
\hline $\begin{array}{l}\text { Steps } \\
\text { (between subjects; free day) }\end{array}$ & 0.75 & $9.837 e-07$ & 0.34 & 0.73 & $-3.63,5.13$ \\
\hline $\begin{array}{l}\text { Steps } \\
\text { (between subjects; school day) }\end{array}$ & -1.70 & $<0.001$ & -0.88 & 0.38 & $-5.50,2.08$ \\
\hline $\begin{array}{l}\text { Steps } \\
\text { (within subjects; free day) }\end{array}$ & 0.62 & 0.001 & 1.76 & 0.08 & $-0.07,1.31$ \\
\hline $\begin{array}{l}\text { Steps } \\
\text { (within subjects; school day) }\end{array}$ & 1.07 & 0.002 & 3.10 & 0.00 & $0.39,1.75$ \\
\hline & \multicolumn{5}{|c|}{ TST (in minutes) } \\
\hline $\begin{array}{l}\text { Steps } \\
\text { (between subjects; free day) }\end{array}$ & -2.64 & $<0.001$ & -1.63 & 0.10 & $-5.81,0.53$ \\
\hline $\begin{array}{l}\text { Steps } \\
\text { (between subjects; school day) }\end{array}$ & -2.03 & $<0.001$ & -1.25 & 0.21 & $-5.19,1.14$ \\
\hline $\begin{array}{l}\text { Steps } \\
\text { (within subjects; free day) }\end{array}$ & -0.07 & $<0.001$ & -0.27 & 0.79 & $-0.61,0.46$ \\
\hline
\end{tabular}




\begin{tabular}{|c|c|c|c|c|c|}
\hline Factor & Coefficient & Cohens $\mathrm{f}^{2}$ & z & $p$ & $95 \% \mathrm{Cl}$ \\
\hline $\begin{array}{l}\text { Steps } \\
\text { (within subjects; school day) }\end{array}$ & -0.47 & $<0.001$ & -1.37 & 0.17 & $-1.13,0.20$ \\
\hline & \multicolumn{5}{|c|}{$\mid \operatorname{varvec} \tilde{S} \backslash$ varvec $E$ (in percent) } \\
\hline $\begin{array}{l}\text { Steps } \\
\text { (between subjects; free day) }\end{array}$ & -0.44 & $<0.001$ & -2.31 & 0.02 & $-0.82,-0.07$ \\
\hline $\begin{array}{l}\text { Steps } \\
\text { (between subjects; school day) }\end{array}$ & -0.43 & $<0.001$ & -2.55 & 0.01 & $-0.75,-0.10$ \\
\hline $\begin{array}{l}\text { Steps } \\
\text { (within subjects; free -day) }\end{array}$ & 0.04 & $<0.001$ & 1.61 & 0.11 & $-0.01,0.10$ \\
\hline $\begin{array}{l}\text { Steps } \\
\text { (within subjects; school day) }\end{array}$ & 0.04 & $<0.001$ & 1.30 & 0.19 & $-0.2,0.11$ \\
\hline
\end{tabular}

Between subjects, we find that people that took more steps on average have lower sleep efficiency on both free and school days $\left(z=2.31, p<0.05, f^{2}=0.00\right.$ free days; $z=2.55, p=0.01, f^{2}=0.00$, school days $)$. Here, taking 1,000 steps more was associated a reduction in sleep efficiency of about $0.44 \%$. No other between subjects' effects were observed.

\section{Discussion}

The aims of the present study were to a) describe physical activity on school and free days using longterm daily objective measurements in a sample of adolescents, and b) investigate the relationship between objectively-measured (i.e., actigraphy) daytime physical activity and sleep. Overall, our results demonstrate that physical activity declined during adolescence, that boys were more active than girls, and both boys and girls were more active on school as compared to free days. When looking at the association between actigraphy-assessed physical activity and sleep, we find that adolescents with more activity on school days, as indexed by mean steps per day, had slightly later bed and rise times as well as somewhat lower sleep efficiency.

As hypothesized, and in line with previous studies $[43,55,56]$ we find that adolescents were less active on free days compared to school days. It is plausible that adolescents are more active during school days due to greater opportunities to participate in physical education classes and extra-curricular organized physical activity. This may be due to formalized physical activity policies at schools, which have been shown to have an influence on children's activity levels [57]. A further explanation for the difference between school and free days may be that on school days adolescents have to travel from home to 
school and have movements between class to class, whereas on free days they are more prone to sedentary behaviors, in particular, screen-related sedentary behavior (i.e., computer use and television viewing) on free days $[55,56]$. Thus, it is not only vital to implement physical activity policies in schools, but it is also essential to promote physical activity on free days.

Furthermore, as expected, we found that male adolescents were more physically active than their female counterparts, a finding that is consistent with previous studies examining physical activity of boys and girls with actigraphy (e.g., [19]). Previous research points to several possible explanations as to why girls are less physically active than boys. For instance, although schools provide opportunities to be physically active during school breaks and physical education class, they might be more readily accessible or desirable to boys. Indeed, in a survey study girls often reported that sports in high school are competitive, which is more likely to be enjoyed by boys [20].

Finally, as hypothesized and in agreement with previous studies conducted in several other countries [58], we found a significant decline in physical activity with increasing age. As this pattern is consistent across settings, it suggests that the decline may be normative during adolescence due to competing interests and additional academic pressure, which may reduce the time available for physical activity [59]. Taken together, these findings demonstrate how social and cultural factors can play a crucial role in the distribution of physical activity. Hence, the consistency of findings across studies highlight the need to consider the unique activity patterns of adolescents and factors influencing physical activity when developing physical activity intervention programs for this population.

Our second hypothesis that higher physical activity would be associated with better sleep quantity and quality was not confirmed. Our findings were inconsistent with some previous epidemiological, experimental and observational studies reporting a beneficial effect of physical activity on sleep [25, 30, 31]. Participants with more steps showed slightly lower sleep efficiency. This was an unexpected finding but in line with a cohort study examining the relationship between actigraphy-assessed physical activity and sleep in 275 Finnish pre-adolescents [38]. Their findings indicated that higher physical activity during the day was associated with shorter sleep duration, lower sleep efficiency and higher fragmentation of sleep the following night. Another explanation for the negative association between physical and sleep might be found in a trait-like inter-individual variability in activity level. For example, the inherent activity level of a child, might manifest itself in a higher activity level during both the day and the night [38]. A meta-analysis containing of 16 studies comparing sleep in children with attention-deficit/hyperactivity disorder (ADHD) versus controls, showed that children with ADHD had more bedtime resistance, sleep onset difficulties and night awakenings [60]. Therefore, it is suggested that the "trait" activity level may not only explain physical activity level during the day but may also define the level of activity during the night [38].

Our within subject finding of more physical activity being associated with later bedtimes may be explained within the context of the current sleep hygiene recommendations that advise against exercise in the evening because of the negative impact on sleep [61]. In a meta-analysis higher exercise intensity 
was associated with prolonged sleep onset latency, lower total sleep time, lower sleep efficiency and more wake after sleep onset, if exercise ended around one hour prior to bedtime [61]. The somewhat detrimental effect of physical activity on sleep may be interpreted through the impact of physical activity on the circadian system. Physical activity can act as a "Zeitgeber" on the circadian system and has been shown to influences the phase of the circadian clock $[62,63]$. Future studies should examine not only the association between physical activity and sleep, but also the timing of physical activity.

The findings in this study need to be interpreted in light of some caveats and limitations. For example, we note that while the impact of physical activity on sleep was statistically significant and robust, the effect sizes are small and the benefits of physical activity likely outweigh the detrimental effects of such activity on sleep. Furthermore, even though the actigraphy is an objective measure, there are still some limitations to it. First, the actigraphy used reported the overall physical activity and was not able to distinguish between different intensity levels. This may be key in explaining the mixed findings. Preliminary evidence suggest that especially vigorous physical activity tends to be a better predictor of favorable sleep patterns $[30,64]$ in comparison to light and moderate physical activity [32, 34]. Second, the time of day in which physical activity occurred was not captured in the study, [34]. Third, the study does not allow any conclusion as to the causal direction of the observed pattern of associations. Fourth, any conclusions have to be made cautiously because the findings are based on a relatively small sample, of which we do not know whether it is representative for all adolescents of this age range since it is based on a data set derived from a twin study. Lastly, the actigraph does not capture physical activity associated with activities in which the wrist is stable - e.g., a participant riding a bicycle, and participants were instructed to take off the actigraph while swimming, which means that this form of physical activity could not be taken into account.

Despite these limitations, the major strength of this study was the long-term examination of the association between physical activity and sleep using different aspects of sleep (actigraphy, and subjective sleep quality) to obtain a comprehensive view of the topic. To the best of our knowledge, this was the first study utilizing all these methods at the same time in a single sample of adolescents. Furthermore, the objective assessment of sleep and activity over several months with the same device in the home environment enhances the reliability of our findings and allowed us to examine potential correlations between physical activity and sleep for both school and free days.

\section{Conclusions}

Our findings obtained through objective and long-term measurement of both sleep and steps challenge previous findings showing a positive effect of the number of steps on sleep. We emphasize the importance of the methodology and the separation of within subject from between subject features when examining the relationship between physical activity and sleep.

\section{List Of Abbreviations}


ICC - intra-class coefficient

TST - total sleep time

SOL - sleep onset latency

WASO - wake after sleep onset

NOA - number of awakenings

SE - sleep efficiency

STEPS_M - mean number of steps across all measurements days for each individual

STEPS_D - baseline levels of steps calculated by subtracting the mean across all days for an individual by the number of steps per day

ADHD - attention-deficit/hyperactivity disorder

\section{Declarations}

\section{Ethics approval and consent to participate}

The study has been performed in accordance with the Declaration of Helsinki and the ethics commission of the canton of Zurich approved the study. Participants and the participants' parents provided written informed consent.

\section{Consent for publication}

Not applicable.

\section{Availability of data and materials}

The datasets used and/or analysed during the current study are available from the corresponding author on reasonable request.

\section{Competing interests}

The authors declare that they have no competing interests

\section{Funding}

The present study was funded by the Jacobs Foundation as well as the Interfaculty Research Cooperation: Decoding Sleep (both assigned to Dr. Leila Tarokh).

\section{Authors' contributions}


CEGFC was a major contributor in writing the manuscript and was involved in the data analysis.

TTT was involved in the writing of the first draft of the manuscript and prepared the data for the analysis.

$\mathrm{SL}$ conducted the data analysis. $\mathrm{CH}$ was involved in data collection and initial analyses. MK was involved in the writing of the manuscript. LT designed the project, was a major contributor in writing the manuscript, involved in data collection and analysis. All authors read and approved the final manuscript.

\section{Acknowledgements}

The authors thank the participants and their families for taking part in the study. We are also deeply grateful to Daniela Rupp, Julia Hegy, Stephanie Leuenberger and Nathaline Margot for help with data acquisition.

\section{References}

1. Gradisar M, Gardner G, Dohnt H. Recent worldwide sleep patterns and problems during adolescence: a review and meta-analysis of age, region, and sleep. Sleep Med. 2011;12:110-8.

2. Crowley SJ, Acebo C, Carskadon MA. Sleep, circadian rhythms, and delayed phase in adolescence. Sleep Med. 2007;8:602-12.

3. Hagenauer MH, Perryman JI, Lee TM, Carskadon MA. Adolescent changes in the homeostatic and circadian regulation of sleep. Dev Neurosci. 2009;31:276-84.

4. Carskadon MA. Sleep in adolescents: the perfect storm. Pediatr Clin North Am. 2011;58:637-47.

5. Crowley SJ, Wolfson AR, Tarokh L, Carskadon MA. An update on adolescent sleep: New evidence informing the perfect storm model. J Adolesc. 2018;67:55-65.

6. Perkinson-Gloor N, Lemola S, Grob A. Sleep duration, positive attitude toward life, and academic achievement: the role of daytime tiredness, behavioral persistence, and school start times. J Adolesc. 2013;36:311-8.

7. Wolfson AR, Carskadon MA. Understanding adolescents' sleep patterns and school performance: a critical appraisal. Sleep Med Rev. 2003;7:491-506.

8. Medic G, Wille M, Hemels ME. Short- and long-term health consequences of sleep disruption. Nat Sci Sleep. 2017;9:151-61.

9. Cookson C. Why sleeping more will help the national economy. Financial Times. 2018. https://www.ft.com/content/e3d2fbc4-db69-11e7-9504-59efdb70e12f. Accessed 8 Feb 2019.

10. National Sleep Foundation. Sleep in America poll: summary of findings. 2006.

11. Bub KL, Buckhalt JA, El-Sheikh M. Children's Sleep and Cognitive Performance: A Cross-Domain Analysis of Change Over Time. Dev Psychol. 2011;47:1504-14.

12. Killgore WDS. Effects of sleep deprivation on cognition. Prog Brain Res. 2010;185:105-29.

13. Louca M, Short MA. The Effect of One Night's Sleep Deprivation on Adolescent Neurobehavioral Performance. Sleep. 2014;37:1799-807. 
14. Curcio G, Ferrara M, De Gennaro L. Sleep loss, learning capacity and academic performance. Sleep Med Rev. 2006;10:323-37.

15. DahI RE, Lewin DS. Pathways to adolescent health sleep regulation and behavior. J Adolesc Health. 2002;31 6 Suppl:175-84.

16. Baum KT, Desai A, Field J, Miller LE, Rausch J, Beebe DW. Sleep restriction worsens mood and emotion regulation in adolescents. Journal of Child Psychology and Psychiatry. 2014;55:180-90.

17. Fredriksen K, Rhodes J, Reddy R, Way N. Sleepless in Chicago: tracking the effects of adolescent sleep loss during the middle school years. Child Dev. 2004;75:84-95.

18. Kredlow MA, Capozzoli MC, Hearon BA, Calkins AW, Otto MW. The effects of physical activity on sleep: a meta-analytic review. J Behav Med. 2015;38:427-49.

19. Cooper AR, Goodman A, Page AS, Sherar LB, Esliger DW, van Sluijs EMF, et al. Objectively measured physical activity and sedentary time in youth: the International children's accelerometry database (ICAD). Int J Behav Nutr Phys Act. 2015;12:113.

20. Slater A, Tiggemann M. "Uncool to do sport": A focus group study of adolescent girls' reasons for withdrawing from physical activity. Psychology of Sport and Exercise. 2010;11:619-26.

21. Ancoli-Israel S. "Sleep is not tangible" or what the Hebrew tradition has to say about sleep. Psychosom Med. 2001;63:778-87.

22. Sherrill DL, Kotchou K, Quan SF. Association of physical activity and human sleep disorders. Arch Intern Med. 1998;158:1894-8.

23. Urponen H, Vuori I, Hasan J, Partinen M. Self-evaluations of factors promoting and disturbing sleep: an epidemiological survey in Finland. Soc Sci Med. 1988;26:443-50.

24. Hirshkowitz M, Whiton K, Albert SM, Alessi C, Bruni O, DonCarlos L, et al. National Sleep Foundation's updated sleep duration recommendations: final report. Sleep Health. 2015;1:233-43.

25. Youngstedt SD. Effects of exercise on sleep. Clin Sports Med. 2005;24:355-65, xi.

26. Driver HS, Taylor SR. Exercise and sleep. Sleep Medicine Reviews. 2000;4:387-402.

27. Steele MM, Richardson B, Daratha KB, Bindler RC. Multiple Behavioral Factors Related to Weight Status in a Sample of Early Adolescents: Relationships of Sleep, Screen Time, and Physical Activity. Children's Health Care. 2012;41:269-80.

28. Bartel KA, Gradisar M, Williamson P. Protective and risk factors for adolescent sleep: a meta-analytic review. Sleep Med Rev. 2015;21:72-85.

29. Brand S, Beck J, Gerber M, Hatzinger M, Holsboer-Trachsler E. Evidence of favorable sleep-EEG patterns in adolescent male vigorous football players compared to controls. World J Biol Psychiatry. 2010;11 2 Pt 2:465-75.

30. Lang C, Brand S, Feldmeth AK, Holsboer-Trachsler E, Pühse U, Gerber M. Increased self-reported and objectively assessed physical activity predict sleep quality among adolescents. Physiol Behav. 2013;120:46-53. 
31. Kalak N, Gerber M, Kirov R, Mikoteit T, Yordanova J, Pühse U, et al. Daily morning running for 3 weeks improved sleep and psychological functioning in healthy adolescents compared with controls. J Adolesc Health. 2012;51:615-22.

32. Lin Y, Tremblay MS, Katzmarzyk PT, Fogelholm M, Hu G, Lambert EV, et al. Temporal and bidirectional associations between sleep duration and physical activity/sedentary time in children: An international comparison. Prev Med. 2018;111:436-41.

33. Ortega FB, Ruiz JR, Labayen I, Kwak L, Harro J, Oja L, et al. Sleep duration and activity levels in Estonian and Swedish children and adolescents. Eur J Appl Physiol. 2011;111:2615-23.

34. Vincent GE, Barnett LM, Lubans DR, Salmon J, Timperio A, Ridgers ND. Temporal and bidirectional associations between physical activity and sleep in primary school-aged children. Appl Physiol Nutr Metab. 2017;42:238-42.

35. Williams SM, Farmer VL, Taylor BJ, Taylor RW. Do More Active Children Sleep More? A Repeated Cross-Sectional Analysis Using Accelerometry. PLOS ONE. 2014;9:e93117.

36. Youngstedt SD, Perlis ML, O'Brien PM, Palmer CR, Smith MT, Orff HJ, et al. No association of sleep with total daily physical activity in normal sleepers. Physiol Behav. 2003;78:395-401.

37. Ekstedt M, Nyberg G, Ingre M, Ekblom Ö, Marcus C. Sleep, physical activity and BMI in six to ten-yearold children measured by accelerometry: a cross-sectional study. International Journal of Behavioral Nutrition and Physical Activity. 2013;10:82.

38. Pesonen A-K, Sjöstén NM, Matthews KA, Heinonen K, Martikainen S, Kajantie E, et al. Temporal Associations between Daytime Physical Activity and Sleep in Children. PLOS ONE. 2011;6:e22958.

39. Lang C, Kalak N, Brand S, Holsboer-Trachsler E, Pühse U, Gerber M. The relationship between physical activity and sleep from mid adolescence to early adulthood. A systematic review of methodological approaches and meta-analysis. Sleep Med Rev. 2016;28:32-45.

40. Acebo C, Sadeh A, Seifer R, Tzischinsky O, Wolfson AR, Hafer A, et al. Estimating sleep patterns with activity monitoring in children and adolescents: how many nights are necessary for reliable measures? Sleep. 1999;22:95-103.

41. Trost SG, Pate RR, Freedson PS, Sallis JF, Taylor WC. Using objective physical activity measures with youth: how many days of monitoring are needed? Med Sci Sports Exerc. 2000;32:426-31.

42. Stone MR, Stevens D, Faulkner GEJ. Maintaining recommended sleep throughout the week is associated with increased physical activity in children. Prev Med. 2013;56:112-7.

43. Craig CL, Cameron C, Griffiths JM, Tudor-Locke C. Descriptive epidemiology of youth pedometerdetermined physical activity: CANPLAY. Med Sci Sports Exerc. 2010;42:1639-43.

44. Inderkum AP, Tarokh L. High heritability of adolescent sleep-wake behavior on free, but not school days: a long-term twin study. Sleep. 2018;41.

45. Rusterholz T, Hamann C, Markovic A, Schmidt SJ, Achermann P, Tarokh L. Nature and Nurture: Brain Region-Specific Inheritance of Sleep Neurophysiology in Adolescence. J Neurosci. 2018;38:9275-85. 
46. Markovic A, Achermann P, Rusterholz T, Tarokh L. Heritability of Sleep EEG Topography in Adolescence: Results from a Longitudinal Twin Study. Sci Rep. 2018;8:7334.

47. Markovic A, Kaess M, Tarokh L. Gender differences in adolescent sleep neurophysiology: a highdensity sleep EEG study. Sci Rep. 2020;10:15935.

48. Markovic A, Kaess M, Tarokh L. Environmental Factors Shape Sleep EEG Connectivity During Early Adolescence. Cereb Cortex. 2020;30:5780-91.

49. Hamann C, Rusterholz T, Studer M, Kaess M, Tarokh L. Association between depressive symptoms and sleep neurophysiology in early adolescence. J Child Psychol Psychiatry. 2019;60:1334-42.

50. Evenson KR, Goto MM, Furberg RD. Systematic review of the validity and reliability of consumerwearable activity trackers. International Journal of Behavioral Nutrition and Physical Activity. 2015;12:159.

51. Ferguson T, Rowlands AV, Olds T, Maher C. The validity of consumer-level, activity monitors in healthy adults worn in free-living conditions: a cross-sectional study. Int J Behav Nutr Phys Act. 2015;12:42.

52. de Zambotti M, Baker FC, Colrain IM. Validation of Sleep-Tracking Technology Compared with Polysomnography in Adolescents. Sleep. 2015;38:1461-8.

53. Selya AS, Rose JS, Dierker LC, Hedeker D, Mermelstein RJ. A Practical Guide to Calculating Cohen's f2, a Measure of Local Effect Size, from PROC MIXED. Front Psychol. 2012;3.

54. StataCorp. 2019. Stata Statistical Software: Release 16. College Station, TX: StataCorp LLC.

55. von Hippel PT, Workman J. From Kindergarten Through Second Grade, U.S. Children's Obesity Prevalence Grows Only During Summer Vacations. Obesity (Silver Spring). 2016;24:2296-300.

56. Sallis JF, Prochaska JJ, Taylor WC. A review of correlates of physical activity of children and adolescents. Med Sci Sports Exerc. 2000;32:963-75.

57. Cradock AL, Melly SJ, Allen JG, Morris JS, Gortmaker SL. Characteristics of School Campuses and Physical Activity Among Youth. American Journal of Preventive Medicine. 2007;33:106-113.e1.

58. Dumith SC, Gigante DP, Domingues MR, Kohl HW. Physical activity change during adolescence: a systematic review and a pooled analysis. Int J Epidemiol. 2011;40:685-98.

59. Allison KR, Adlaf EM, Dwyer JJM, Lysy DC, Irving HM. The decline in physical activity among adolescent students: a cross-national comparison. Can J Public Health. 2007;98:97-100.

60. Cortese S, Faraone SV, Konofal E, Lecendreux M. Sleep in children with attention-deficit/hyperactivity disorder: meta-analysis of subjective and objective studies. J Am Acad Child Adolesc Psychiatry. 2009;48:894-908.

61. Stutz J, Eiholzer R, Spengler CM. Effects of Evening Exercise on Sleep in Healthy Participants: A Systematic Review and Meta-Analysis. Sports Med. 2019;49:269-87.

62. Kemler D, Wolff CA, Esser KA. Time-of-day dependent effects of contractile activity on the phase of the skeletal muscle clock. The Journal of Physiology. 2020;598:3631-44.

63. Youngstedt SD, Elliott JA, Kripke DF. Human circadian phase-response curves for exercise. The Journal of Physiology. 2019;597:2253-68. 
64. Gerber M, Brand S, Herrmann C, Colledge F, Holsboer-Trachsler E, Pühse U. Increased objectively assessed vigorous-intensity exercise is associated with reduced stress, increased mental health and good objective and subjective sleep in young adults. Physiol Behav. 2014;135:17-24.

\section{Figures}
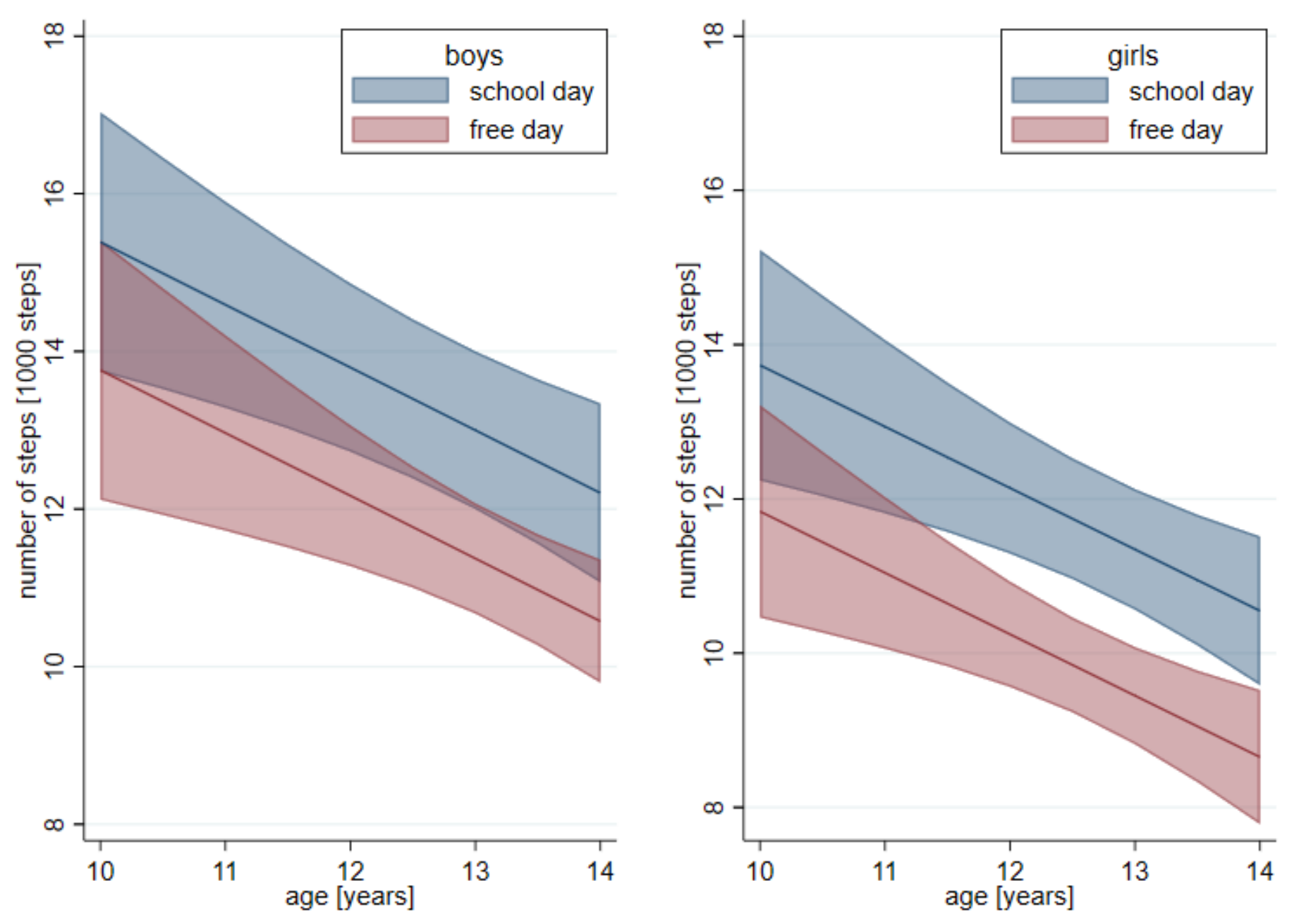

\section{Figure 1}

Predicted number of steps. Number of steps (in 1000 steps) is shown on the y-axis while age (in years) is on the x-axis. On the left side we see the predicted activity for boys and on the right side for girls (in blue for school days, in red for free days). 